Portland State University

PDXScholar

Civil and Environmental Engineering Faculty

Publications and Presentations

Civil and Environmental Engineering

$9-2017$

\title{
Topographic and Frictional Controls on Tides in the Sea of Okhotsk
}

\author{
Edward Zaron \\ Portland State University, ezaron@pdx.edu
}

Follow this and additional works at: https://pdxscholar.library.pdx.edu/cengin_fac

Part of the Engineering Commons

Let us know how access to this document benefits you.

\section{Citation Details}

Zaron, Edward, "Topographic and Frictional Controls on Tides in the Sea of Okhotsk" (2017). Civil and Environmental Engineering Faculty Publications and Presentations. 437.

https://pdxscholar.library.pdx.edu/cengin_fac/437

This Article is brought to you for free and open access. It has been accepted for inclusion in Civil and Environmental Engineering Faculty Publications and Presentations by an authorized administrator of PDXScholar. Please contact us if we can make this document more accessible: pdxscholar@pdx.edu. 


\title{
Topographic and Frictional Controls on Tides in the Sea of Okhotsk
}

\author{
Edward D. Zaron* \\ Department of Civil and Environmental Engineering, Portland, Oregon, USA
}

\begin{abstract}
The sensitivity of barotropic tides to bottom topography and frictional parameters has been studied in a model for the Sea of Okhotsk. This region was chosen because of the paucity of bathymetry data and the possibility of using satellite altimeter data to better identify the bottom topography using variational inverse methods. The sensitivity was studied using both the direct and adjoint sensitivity. In the former approach, perturbations to the nominal model were applied to examine their impact; in the latter approach, the sensitivities were computed using the adjoint of the tangent linearization of the dynamical model. It is found that small-scale coastal near-resonant amplification controls the tidal dynamics, and the sensitivity of the solutions is dominated by topography in these regions, far exceeding the influence of other factors. Consequently, the tidal dynamics and resonant amplification creates a non-local relationship between water level and bottom topography and leads to a linear dependence of measurements upon a very few degrees of freedom. The results indicate severe limitations on inverse approaches for
\end{abstract}

\footnotetext{
* Corresponding author

Email address: ezaron@pdx.edu (Edward D. Zaron)
} 
identification of topography, and add to the rationale for the collection and sharing of high quality bathymetry data to enable improved ocean modeling. Keywords:

tide, adjoint sensitivity, bottom topography

2

3

4

5

\section{Introduction}

Numerical modelers of the coastal ocean have long recognized the importance of bottom topography for making accurate models of tides and water levels (Lefevre et al., 2000). The bottom topography is here defined as the two-dimensional field of water depth, i.e., the vertical distance between the mean water surface and the material bottom. The term bathymetry is sometimes used to refer to bottom topography; however, here the usage of bathymetry shall be restricted to refer to measurements of water depth via hydrographic surveys (Organization, 1998), rather than referring to the twodimensional depth field.

Bottom topography influences the flow fields through several distinct mechanisms. First, bottom topography defines the lower material boundary of the ocean, which provides kinematic constraints on the flow. Second, at a given location, the water depth is related to the mass of the water column and determines the acceleration resulting from a horizontal force; the speed of wave propagation is thus set by water depth. And, finally, the ocean bottom is obviously the locus of boundary layer processes, and these support tangential stresses that may influence entire the water column. Although the detailed representation of these physics differs depending on the setting, their manifestations on wave processes, material transport, vorticity 
dynamics, and dissipative processes are frequently significant.

It can be a challenge for ocean modelers to obtain the topography needed to create credible ocean simulations. The availability of bathymetry obtained via ordinary or multibeam sonar varies greatly as a function of geographic location (Wessel and Chandler, 2011), and the accuracy of older measurements is not well characterized (Jakobsson et al., 2002; Marks and Smith, 2008). In data from the pre-satellite era, the navigational or geolocation error $(20$ $\mathrm{km}$ being a typical magnitude, Smith 1993) contributes the most to uncertainty in depth, in direct proportion to the slope of the bottom (Jakobsson et al., 2005). At the interface between the continental shelf and slope, the error in depth can be 100's of meters (Marks and Smith, 2005; Inazu et al., 2009). Other sources of error include the uncertain vertical datum, when the measured depth is significantly altered by tides or other time-variable water depth which is not corrected, error due to the non-vertical orientation of the sonar beam, and error in the speed of sound used to convert travel time to distance (Marks and Smith, 2008). Smith and Sandwell (1994) pioneered the use of the marine gravity field for inferring bottom topography in the deep ocean, where sediments are uniform and the relationship between gravity and topography can be inferred. This approach is less accurate over the continental shelves and regions of complex geology (Marks and Smith, 2012), where dense in situ data are necessary to control the gravimetry-based estimates (Marks et al., 2010; Marks and Smith, 2012).

In order to deal with these uncertainties, it is typical in the course of model development to examine the sensitivity of the solution to changes in the source of the topography and the degree of smoothing, as well as factors such 
as grid resolution (Hirose et al., 2001). And, sometimes, the topography is calibrated or adjusted to improve the model performance (Ten-Brummelhuis et al., 1993; Lyard and Genco, 1994; Hirose, 2005; Cea and French, 2012).

The present study was motivated by the hypothesis that an inverse modeling approach could usefully improve the accuracy of bottom topography over continental shelves at locations where bathymetry is sparse and gravimetricallyderived topography is inaccurate. The barotropic tides are probably the most-precisely measured and predictable phenomena involving the oceans at continental-shelf scale (Stammer et al., 2014), so the inverse approach was developed by assimilating altimeter-derived water elevation measurements into a dynamical tide model. The technical approach involved re-working the implementation of Zaron et al. (2011) to the frequency domain by augmenting the approach of Egbert et al. (1994) with topography as a distributed control parameter. Poor results with the inverse approach and unexpected sensitivity to the spatial correlation model for the topographic error led to the more fundamental investigation of model sensitivity described in the present article.

This paper is organized as follows. In Section 2, the concepts of the forward and adjoint sensitivity are defined and their application to a barotropic shallow water model of tidal dynamics is reviewed. In Section 3, an overview of the factors influencing the accuracy of tide models in the Sea of Okhotsk is conducted in order to define the relative importance of bottom topography, grid resolution, frictional parameterization, and non-linear tidal interactions. In Section 4, the adjoint sensitivity is used to quantify the sensitivity of tidal elevation to topography and friction, and the linear dependence of the ad- 
joint sensitivity functions is examined. In Section 5, the findings of Section 4 are related to a previous idealized study that emphasized the significance of tidal resonances near the coastline, and other implications of the results are discussed. Section 6 summarizes the results.

\section{Methodology}

\subsection{Tide Model and Dynamics}

The tidal dynamics are expressed in terms of the horizontal volume transport vector, $\mathbf{U}$, comprised of zonal and meridional components $(U, V)$, and the water surface elevation, $\eta$, which are functions of latitude, $\theta$, longitude, $\phi$, and time, $t$. The time-varying fields $(\mathbf{U}, \eta)$ are expanded as the sum of contributions from $k=1, \ldots, N_{c}$ astronomical tidal constituents in the present case,

$$
\mathbf{U}(\phi, \theta, t)=\sum_{k=1}^{N_{c}} \operatorname{Re}\left[\mathbf{U}^{(k)}(\phi, \theta) \exp \left(-i \omega_{k} t\right)\right]
$$

$$
\eta(\phi, \theta, t)=\sum_{k=1}^{N_{c}} \operatorname{Re}\left[\eta^{(k)}(\phi, \theta) \exp \left(-i \omega_{k} t\right)\right],
$$

where $\left(\mathbf{U}^{(k)}, \eta^{(k)}\right)$ are complex-valued harmonic constants for the transport and surface elevation fields, and $\omega_{k}$ are the frequencies of tides. In the present case, no more than $N_{c}=8$ constituents shall be considered, corresponding to the $\mathrm{M}_{2}, \mathrm{~K}_{1}, \mathrm{~S}_{2}, \mathrm{O}_{1}, \mathrm{~N}_{2}, \mathrm{P}_{1}, \mathrm{~K}_{2}$, and $\mathrm{Q}_{1}$ tides, for $k=1, \ldots, 8$, repectively. Henceforth the notation indicating a particular frequency $(k)$ shall be omitted except when necessary in expressions involving more than a single frequency.

Tidal dynamics are governed approximately by the Laplace Tidal Equations (LTE) augmented with a linear approximation of the quadratic bottom 
106

drag law (Snyder et al., 1979) and a modified astronomical tide generating force (ATGF) which accounts for solid Earth loading and ocean selfattraction (Egbert et al., 1994). The LTE are given by,

$$
\begin{aligned}
-i \omega \mathbf{U}+f \times \mathbf{U}+g H \nabla(\eta-\Phi)+C_{d} u_{f} \frac{\mathbf{U}}{H} & =0 \\
-i \omega \eta+\nabla \cdot \mathbf{U} & =0
\end{aligned}
$$

where $f=2 \Omega \sin \theta \hat{k}$ is the local vertical component of the Coriolis parameter, $g=9.81 \mathrm{~m} / \mathrm{s}^{2}$ is gravitational acceleration, $H$ is the bottom topography, $C_{d}=2.5 \times 10^{-3}$ is the bottom drag coefficient, and $u_{f}$ is an estimate for the time-average near-bottom current speed. The domain, denoted $\mathcal{D}$, has boundary, $\partial \mathcal{D}$, comprising closed (material) and open boundary segments, denoted $\partial \mathcal{D}_{1}$ and $\partial \mathcal{D}_{2}$, respectively. Boundary conditions are no-normal flow on $\partial \mathcal{D}_{1}$,

$$
(U, V) \cdot \boldsymbol{n}=0,
$$

and specified surface elevation, $\eta_{d}$, on $\partial \mathcal{D}_{2}$,

$$
\eta=\eta_{d}
$$

The LTE are thus forced by the modified ATGF, $\Phi$, and by open boundary conditions on tidal elevation $\eta$. In spherical polar coordinates the gradient and divergence operators are given by,

$$
\nabla \eta=\left(\frac{1}{a \cos \theta} \frac{\partial \eta}{\partial \phi}, \frac{\partial \eta}{a \partial \theta}\right),
$$

and

$$
\nabla \cdot \mathbf{U}=\frac{1}{a \cos \theta} \frac{\partial U}{\partial \phi}+\frac{1}{a \cos \theta} \frac{\partial(V \cos \theta)}{\partial \theta},
$$

where $a=6.7308 \times 10^{3} \mathrm{~km}$ is the radius of the Earth. 
In order to model the frictional coupling of different frequencies, $u_{f}$ is computed from the tidal currents, $\mathbf{U}^{(k)} / H$, and non-tidal current, $u_{0}$ (Snyder et al., 1979), as

$$
u_{f}=\left(u_{0}^{2}+\gamma_{f} \frac{1}{2 H^{2}} \sum_{k}\left|\mathbf{U}^{(k)}\right|^{2}\right)^{1 / 2} .
$$

The optimal value of the coefficient $\gamma_{f}$ is related to the frequency content of the tides and may be found by analysis of the quadratic bottom stress (Dronkers, 1964; Snyder et al., 1979; Lavelle and Mofjeld, 1983). Here the values $\gamma_{f}=1$ and $u_{0}=0.25 \mathrm{~m} / \mathrm{s}$ are used so that $u_{f}$ is simply the rootmean-square current speed accounting for the resolved tides and a constant non-tidal current. Even with this approximation, the solution of (3)-(6) is iterative, with $u_{f}$ being evaluated from currents computed at the previous iteration. In practice, 5 iterations are typically used to produce stable estimates of $u_{f}$ which differ by less than a few percent from previous values.

Note that $(\mathbf{U}, \eta)$ depends on tidal frequency $(k)$, but $H$ and $C_{d}$ do not depend on $(k)$. Thus, in addition to the coupling through $u_{f}$, the equations for $\left(\mathbf{U}^{(k)}, \eta^{(k)}\right)$, (3)-(4), are implicitly coupled via $H$ and $C_{d}$. Additional nonlinearity in the shallow water equations has been omitted from the LTE without detailed justification. Later, in Section 3, some of these nonlinearities shall be examined in more detail by using a specific solution of the LTE to diagnose these terms.

\subsection{Forward Sensitivity}

Suppose the topography and/or drag coefficient are perturbed from background fields, $H=\bar{H}+H^{\prime}$ and $C_{d}=\bar{C}_{d}+C_{d}^{\prime}$. Assuming the corresponding background fields, $\left(\overline{\mathbf{U}}, \bar{\eta}, \bar{H}, \bar{C}_{d}\right)$, are solutions of equations (3)-(4), the 
$\left(\mathbf{U}^{\prime}, \eta^{\prime}, H^{\prime}, C_{d}^{\prime}\right)$ perturbations approximately satisfy the tangent-linearization of the LTE,

$$
\begin{aligned}
-i \omega \mathbf{U}^{\prime}+f \times \mathbf{U}^{\prime}+g \bar{H} \nabla \eta^{\prime}+\bar{C}_{d} u_{f} \frac{\mathbf{U}^{\prime}}{\bar{H}}+g H^{\prime} \nabla(\bar{\eta}-\Phi)+ & \\
C_{d}^{\prime} u_{f} \frac{\overline{\mathbf{U}}}{\bar{H}}-\bar{C}_{d} u_{f} \frac{\overline{\mathbf{U}}}{\bar{H}^{2}} H^{\prime} & =0 \\
-i \omega \eta^{\prime}+\nabla \cdot \mathbf{U}^{\prime} & =0,
\end{aligned}
$$

with homogeneous boundary conditions on $\partial \mathcal{D}_{1}$ and $\partial \mathcal{D}_{2}$.

The typical approach to assessing the sensitivity of a solution to perturbations of topography or drag coefficient involves differencing solutions of (3)-(4) obtained with different $H$ or $C_{d}$ fields. When either $H^{\prime}$ or $C_{d}^{\prime}$ are given, the so-called forward sensitivity of $y=(\mathbf{U}, \eta)$ may be directly computed from the Gâteaux derivative (Andrews and Hopper, 2011),

$$
\frac{\partial y}{\partial \tau}\left(\bar{H}, \overline{C_{d}} ; H^{\prime}, C_{d}^{\prime}\right)=\lim _{\tau \rightarrow 0} \frac{y\left(\bar{H}+\tau H^{\prime}, \overline{C_{d}}+\tau C_{d}^{\prime}\right)-y\left(\bar{H}, \overline{C_{d}}\right)}{\tau},
$$

where the notation makes it clear that the derivative depends on both the background state and the direction of the perturbation. The code implementing the tangent-linear LTE has been tested to verify its correctness in the limit $\tau \rightarrow 0$, but the examples shown use finite-amplitude perturbations with $\tau=1$. Although there are significant nonlinear components of the sensitivities in the LTE model, they are not pertinent to the overall conclusions and will not be discussed below.

\subsection{Adjoint Sensitivity}

While the forward sensitivity can be computed for a given perturbation, $\left(H^{\prime}, C_{d}^{\prime}\right)$, it is sometimes useful to consider the sensitivity of a particular 
quantity to any possible perturbation. This kind of object, the derivative of a scalar functional of the fields with respect to all possible perturbations, is often called the adjoint sensitivity (Errico, 1997). The adjoint sensitivity provides information about particular changes in the output fields, say, elevation at a given point, as a function of arbitrary perturbations, which are not specified a priori. Generalizing the notation introduced above, let $x=\left(H, C_{d}\right)$. The perturbation outputs, $y^{\prime}=\left(U^{\prime}, \eta^{\prime}\right)$, can be computed from perturbation inputs, $x^{\prime}=\left(H^{\prime}, C_{d}^{\prime}\right)$, as,

$$
y^{\prime}=\int_{\mathcal{D}}\left[\frac{\partial y}{\partial x}\right] x^{\prime}
$$

where the expression $\frac{\partial y}{\partial x}$ is the Fréchet derivative (Andrews and Hopper, 2011), an integro-differential operator. It is difficult to visualize $\frac{\partial y}{\partial x}$ directly, but it is straightforward to visualize the derivative of a scalar functional of $y$

$$
u_{i}=\int_{\mathcal{D}} \kappa_{i} y^{\prime}
$$

where, for example, the kernel $\kappa_{i}$ might represent a delta-function applied to the $\eta$-component of $y$, so that $u_{i}$ measures the water elevation at a particular point, indexed $i$, in the domain. The perturbed measurement would then be given by,

$$
u_{i}=\int_{\mathcal{D}}\left[\int_{\mathcal{D}} \kappa_{i} \frac{\partial y}{\partial x}\right] x^{\prime},
$$

where the expression, $\int_{\mathcal{D}} \kappa_{i} \frac{\partial y}{\partial x}$, is analogous to the $i$-th row of a finite-dimensional Jacobian matrix (Bennett, 1992, 2002).

The object $(\lambda, c)=\int_{\mathcal{D}} \kappa_{i} \frac{\partial y}{\partial x}$ is the adjoint sensitivity. It contains components, $(\lambda, c)$, corresponding to the $\left(H^{\prime}, C_{d}^{\prime}\right)$ components of $x^{\prime}$ in equation (13). 
When equation (13) is written out for the tangent-linear LTE, one may integrate by parts to obtain the following system to compute $(\lambda, c)$ for a given measurement kernel $\kappa_{i}$,

$$
\begin{gathered}
i \omega \boldsymbol{\mu}-f \times \boldsymbol{\mu}-\nabla \zeta+\bar{C}_{d} u_{f} \frac{\boldsymbol{\mu}}{\bar{H}}=0 \\
i \omega \zeta-\nabla \cdot(g \bar{H} \boldsymbol{\mu})=-\kappa_{i} \\
\lambda=-\sum_{k} \operatorname{Re}\left[g \boldsymbol{\mu}^{*(k)} \cdot \nabla\left(\bar{\eta}^{(k)}-\Phi^{(k)}\right)-\bar{C}_{d} u_{f} \frac{\boldsymbol{\mu}^{*(k)} \cdot \overline{\mathbf{U}}^{(k)}}{\bar{H}^{2}}\right] \\
c=-\sum_{k} \operatorname{Re}\left[u_{f} \frac{\boldsymbol{\mu}^{*(k)} \cdot \overline{\mathbf{U}}^{(k)}}{\bar{H}}\right] .
\end{gathered}
$$

Boundary conditions on $\partial D_{2}$ are,

$$
\boldsymbol{\mu} \cdot \boldsymbol{n}=0,
$$

and on $\partial \mathcal{D}_{1}$ are,

$$
\zeta=0 .
$$

Similar to $(\lambda, c)$ and $\left(H, C_{d}\right)$, the adjoint fields $(\boldsymbol{\mu}, \zeta)$ correspond to the physical fields $(\mathbf{U}, \eta)$; however, unlike $\left(H, C_{d}, \lambda, c\right)$, the fields $(\mathbf{U}, \eta, \boldsymbol{\mu}, \zeta)$ depend on tidal frequency $(k)$. Note that the adjoint fields also depend on $\kappa_{i}$, the measurement kernel, and $\left(\overline{\mathbf{U}}, \bar{\eta}, \bar{H}, \bar{C}_{d}\right)$, the background fields; the frictional speed, $u_{f}$, is also a function of $(\bar{H}, \overline{\mathbf{U}})$. Unlike the direct sensitivity, the adjoint sensitivity does not depend on $\left(H^{\prime}, C_{d}^{\prime}\right)$. The computations involved in the adjoint system, (16)-(21), are implemented by taking the adjoint of the finite-difference implementation of the tangent-linear system, (10)-(11).

In the examples to be shown below, the measurement kernel, $\kappa_{i}$, corresponds to the in-phase or quadrature (i.e., real or imaginary component) 
harmonic constant of water surface elevation of the $k$-th tidal frequency at particular latitude and longitude coordinates. One solves equations (16)(19) to compute $\left(\lambda_{i}, c_{i}\right)$ for the given $\kappa_{i}$. The perturbation water elevation, $\eta^{\prime}\left(\theta_{i}, \phi_{i}\right)$, for a particular $H^{\prime}$ is then given by the inner product of $\lambda$ and $H^{\prime}$,

$$
\eta^{\prime}=\int_{\mathcal{D}} \lambda_{i} H^{\prime}
$$

Instead of specifying $H^{\prime}$ or $C_{d}^{\prime}$ a priori, one specifies the measurement kernel, $\kappa_{i}$, and computes the fields $(\lambda, c)$ which $\eta$ is sensitive to.

\section{Tides and Tide Model Sensitivities in the Sea of Okhotsk}

Some of the largest tides in the world are found in the Sea of Okhotsk. For reference, cotidal charts for $\mathrm{M}_{2}$ and $\mathrm{K}_{1}$ tides from the data assimilating TPXO7.2 model (Egbert and Erofeeva, 2002) are shown in Figure 1, and these agree closely with the earlier estimates of Kowalik and Polyakov (1998). Semi-diurnal tides are amplified at Udskaya Guba (Uda Bay), in the west, where the $\mathrm{M}_{2}$ amplitude reaches $3.0 \mathrm{~m}$. Diurnal tides are amplified in the Shelikhov Gulf and in Penzhinskaya Guba (Penzhina Bay), in the northeast, where $\mathrm{K}_{1}$ amplitudes exceed $3.0 \mathrm{~m}$; although, the TPXO7.2 solution does not capture the highest values. The large tidal elevations are associated with strong tidal currents, which cause vertical mixing and play a role in the generation of water masses in the North Pacific (Shcherbina et al., 2004).

To understand the topographic and frictional controls on tides, it is useful to compare the TPXO7.2 model with purely dynamical (not data assimilating) models based on slightly different topographic grids and different friction coefficients. Two independent estimates of topography are used. The first is 
the Digital Bathymetric Database version 3.0 (DBDB2v30) which is based on a compilation of digitized bathymetric charts and other data blended and gridded at uniform 2-minute resolution (Dong Shan Ko, personal communication; Ko 2010). The second is the ETOPO1 topography (Amante and Eakins, 2009) which, in the Sea of Okhotsk, is a hand-edited version of the topography inferred by combining sounding data with satellite-altimeter derived marine gravity data (Smith and Sandwell, 1997). The tidal fields shown in Figure 2 are computed from a numerical LTE solver on an approximately $3 \mathrm{~km}$ horizontal resolution grid using the two dominant tidal constituents, $\mathrm{M}_{2}$ and $\mathrm{K}_{1}$, with elevation on the open ocean boundary provided by TPXO7.2. The numerical implementation is described in detail in Egbert and Erofeeva (2002).

The tides obtained with different bottom topographies differ substantially. For $\mathrm{M}_{2}$, the most apparent difference is the larger tide in the northeast in the Shelikhov Gulf, an enhancement of resonance caused by the different topography. One also notes the large-scale rotation of $30^{\circ}$ of the phase around the amphidromes. Both of the tide models in Figure 2 display much larger $\mathrm{K}_{1}$ amplitudes compared to the TPXO7.2 model, which is not well constrained by data in the Shelikhov Gulf. The differences between the ETOPO1 and DBDDB2v30 solutions extend throughout the central Sea of Okhotsk, with $\mathrm{K}_{1}$ tide in the DBDB2v30 model being much larger than in the ETOPO1 model.

Several other tide models were developed using the ETOPO1 topography in order to assess the significance of the topography relative to model resolution, drag coefficient, and number of tidal constituents included. Table 1 
summarizes the error statistics of the ETOPO1-based model for different versions using $N_{c}=1,2,4$, and 8 constituents corresponding to the constituents listed in Section 2.1. The tabulated root-mean-square vector error (RMSVE) is equal to one-half the square root of the sum of the squared errors between the modeled and observed in-phase and quadrature components of the harmonic constants; the RMSVE is equal to the root-mean-square of the mean difference in time of the partial tide. The data in this case come from the merged records of the TOPEX/POSEIDON, Jason-1, and Jason-2 altimeter missions, which have been harmonically analyzed at each point along the satellite ground tracks (Ray, 1998; Carrère et al., 2004), and then averaged over approximately $150 \mathrm{~km}$ segments to obtain values at the orbit cross-over points (Figure 1a). In order to retain only the highest quality data, data are not used at points with more than $10 \%$ missing data owing to seasonal sea ice or land-contamination of radiometer data used for the wet-troposphere correction.

Table 1 indicates that the RMSVE is relatively insensitive to both model resolution and $N_{c}$. For $N_{c} \geq 2$, the RMSVE for $\mathrm{M}_{2}$ ranges from $3.1 \mathrm{~cm}$ to $4.1 \mathrm{~cm}$, which is smaller than the RMSVE difference between the nominal ETOPO1 solution $(3.2 \mathrm{~cm})$ and the TPXO7.2 reference solution $(1.3 \mathrm{~cm})$. Similarly, the $\mathrm{K}_{1}$ range, $4.7 \mathrm{~cm}$ to $6.0 \mathrm{~cm}$, is smaller than the difference between the nominal ETOPO1 solution $(4.8 \mathrm{~cm})$ and the TPXO7.2 reference solution $(2.7 \mathrm{~cm})$. Thus, the ETOPO1 model cannot be substantively improved compared to the TPXO7.2 model by changing either the grid resolution $(3 \mathrm{~km})$ or the number of tidal constituents $\left(N_{c}=2\right)$.

The ETOPO1-based model has also been run using a range of values for 
Table 1: Root-mean-square vector error (RMSVE, units of $\mathrm{cm}$ ) of models versus observed $\mathrm{M}_{2} \& \mathrm{~K}_{1}$. For comparison, the RMSVE of the TPXO7.2 model is $1.3 \mathrm{~cm}$ for $\mathrm{M}_{2}$, and $2.7 \mathrm{~cm}$ for $\mathrm{K}_{1}$.

\begin{tabular}{ccccccc} 
& \multicolumn{2}{c}{$\mathrm{M}_{2}$ RMSVE $[\mathrm{cm}]$} & \multicolumn{3}{c}{$\mathrm{K}_{1}$} & RMSVE [cm] \\
$N_{c}$ & $4.5 \mathrm{~km}$ & $3 \mathrm{~km}$ & $2 \mathrm{~km}$ & $4.5 \mathrm{~km}$ & $3 \mathrm{~km}$ & $2 \mathrm{~km}$ \\
\hline 1 & 3.9 & 3.1 & 3.5 & n.a. & n.a. & n.a. \\
2 & 4.1 & 3.2 & 3.7 & 6.0 & 4.8 & 5.4 \\
4 & 4.0 & 3.1 & 3.6 & 6.0 & 4.7 & 5.3 \\
8 & 4.0 & 3.1 & 3.6 & 5.9 & 4.6 & 5.3 \\
\hline
\end{tabular}

the bottom drag coefficient, $C_{d}$, from $C_{d}=0.5 \times 10^{-3}$ to $C_{d}=10 \times 10^{-3}$. The RMSVE of the ETOPO1-based model varies from about 3 to $6 \mathrm{~cm}$ over this range (Figure 3 ). The $\mathrm{M}_{2}$ RMSVE is optimized at approximately $C_{d}=2.25 \times 10^{-3}$, while the $\mathrm{K}_{1}$ RMSVE is optimized at $C_{d}=6.0 \times 10^{-3}$. In both cases, though, the RMSVE changes due to $C_{d}$ are much less than the changes due to topography. The RMSVE obtained using the DBDB2v30 topography (with the same $3 \mathrm{~km}$ resolution, $N_{c}=2$, and $C_{d}=2.5 \times 10^{-3}$ used for ETOPO1) is more than 2 times larger than the RMSVE of the ETOPO1-based model (Figure 3).

The DBDB2 and ETOPO1 topographic grids are both plausible estimates of topography, given the sparsity of soundings in the Sea of Okhotsk, but the ETOPO1 topography definitely contains smaller-scale features than DBDB2v30 (Figure 4). The difference field reveals that there are also largerscale differences that extend throughout much of the middle of the Sea (Fig- 
ure 5a). Of course, the largest differences occur near where topographic gradients are largest, offshore of the Kuril Islands, but, as will be shown quantitively, below, these differences occur in deeper water and are less significant to tides within the Sea. The large scale differences in the middleand eastern parts of the main basin are about $150 \mathrm{~m}$, which is more than $10 \%$ of the depth in many places.

Figure 5b shows the sparsity of in situ bathymetry available in the region. The points shown in black are the bathymetric control points used in version 9.1 of the Smith \& Sandwell bottom topography, which is contemporary with the ETOPO1 topography from 2009. Comparison with independent bathymetry from the region $\left(50^{\circ} \mathrm{N}, 148^{\circ} \mathrm{E}\right)-\left(55^{\circ} \mathrm{N}, 151^{\circ} \mathrm{E}\right)$ (cruise MR06-04 obtained from the Japan Agency for Marine-Earth Science and Technology (JAMSTEC) ${ }^{1}$ ) finds standard errors of about $60 \mathrm{~m}$ and $80 \mathrm{~m}$ for DBDB2 and ETOPO1, respectively. Thus, even though the DBDB2v30 is much smoother than ETOPO1, it appears to be of comparable accuracy. The ETOPO1 grid, being derived largely from altimetry, contains errors related to the uncertain relation between marine gravity and topography in this region (Marks and Smith, 2012), and without additional validation data it is difficult to verify that the small-scale structure is accurate.

In summary, a comparison of tide models indicates that bottom topography has the greatest impact on the tidal fields, considering a plausible range of changes in physical and numerical model parameters.

Nonetheless, there are other factors which cannot easily be examined

\footnotetext{
${ }^{1}$ http://www.godac.jamstec.go.jp/
} 
within the context of using a single numerical model. For example, in spite of the examination of various values for the bottom drag coefficient, it is difficult to justify any particular choice for $C_{d}$. The quadratic drag law is a bulk model for the turbulent stress at the bottom, which depends on shear and stratification throughout the water column, non-tidal currents, as well as the physical characteristics of the bottom itself (Grant and Madsen, 1979; Xing and Davies, 1995; Perlin et al., 2005). The linearization of the quadratic drag law introduces additional uncertainty in the value of $u_{f}$ which can also be lumped into $C_{d}$ (Snyder et al., 1979). And, in the Sea of Okhotsk, there is seasonal sea ice, which adds more friction in the mean (Godin, 1986). The numeric size of the drag term is expected to be essentially negligible in water deeper than $50 \mathrm{~m}$, so it is only drag near the coast which is likely significant. Figure 6 illustrates this quantitatively by plotting a friction number, $R_{f}$, defined by,

$$
R_{f}^{2}=\frac{\left(C_{d} u_{f}\left|\mathbf{U}^{(k)}\right| / H\right)^{2}}{\left(\omega_{k}\left|\mathbf{U}^{(k)}\right|\right)^{2}+\left(C_{d} u_{f}\left|\mathbf{U}^{(k)}\right| / H\right)^{2}},
$$

which measures the size of the frictional terms in the momentum equations (3). This quantity is a function of tidal frequency $(k)$ and the $\mathrm{M}_{2}$ field is shown in the figure; the corresponding balance for $K_{1}$ is similar (not shown). The frictional term dominates the term balance in shallow water, but $R_{f}$ is never larger than 0.5 in water deeper than $100 \mathrm{~m}$ (Figure 6). Thus, factor of two or larger mis-specification of the frictional parameters $\left(C_{f}, u_{0}\right.$, and $\left.\gamma_{f}\right)$ ought to influence the term balance only in the shallow regions shown.

The final factor to consider is the validity of other approximations implicit in the LTE, namely, the neglect of the advective nonlinearity and the neglect of the flooding and drying processes at the coastline. The impact of 
these approximations can be compared with the drag terms by looking at the relevant non-dimensional parameters. Advection is quantified with the bulk Froude number, estimated as the ratio of the friction velocity (which incorporates all the tidal currents, plus the non-tidal current speed, $u_{0}$ ) to the shallow water phase speed in the absence of rotation,

$$
F r=\frac{u_{f}}{\sqrt{g H}} .
$$

The Froude number is the appropriate measure of the advective nonlinearity when the pressure gradient is among the dominant terms. This field is illustrated in Figure $7 \mathrm{~b}$, where it is compared with $R_{f}$ in a close-up of Udskaya Guba. The $\mathrm{Fr}$ field approaches 0.5 in some of the shallowest regions near the coast, but these are always contained within the region where friction dominates. Likewise, the vertical excursion number, $Z$, may be defined which measures the tidal range in comparison with mean water depth,

$$
Z^{2}=\frac{1}{2} \sum_{k}\left|\eta^{(k)}\right|^{2} / H^{2} .
$$

Significant values of $Z$ indicate the potential for inundation within a much smaller region than encompassed by frictional or advective influences; although, the presence of inundation per se might alter dissipation which could have larger-scale impacts.

\section{Adjoint Sensitivities in the Sea of Okhotsk}

The most direct way to assess the sensitivity of tidal fields to topography or drag is by computing solutions of the adjoint LTE system. Here this is done by computing the $\lambda$ and $c$ fields defined in equations (18) and (19). The 

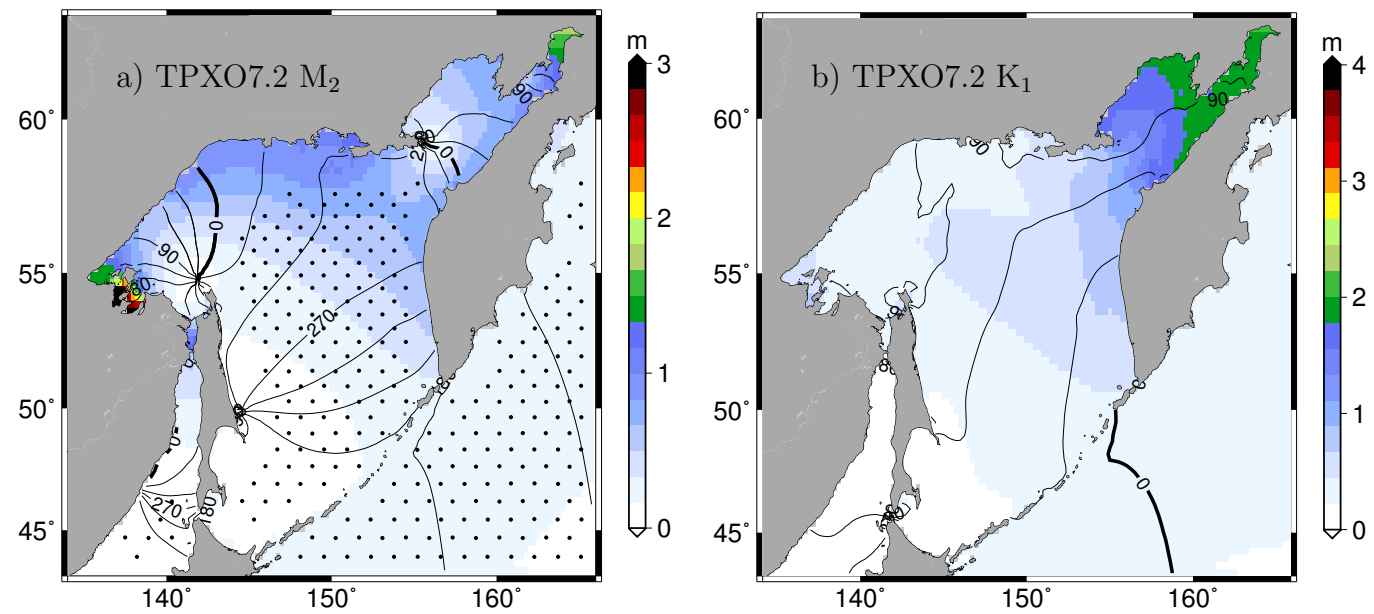

Figure 1: TPXO7.2 tide model for the (a) $\mathrm{M}_{2}$ and (b) $\mathrm{K}_{1}$ tides. Tidal amplitude is shown with the color scale, which is different for $\mathrm{M}_{2}$ and $\mathrm{K}_{1}$. Greenwich phase lag is shown with solid lines in increments of $30^{\circ}$. Solid dots in (a) are locations of satellite altimeter data used to compute the error statistics summarized in Table 1.

measurement kernel, $\kappa_{i}$, is a delta-function corresponding the measurement of the in-phase $\mathrm{M}_{2}$ component of $\eta^{(k)}$ at mid-basin, near $55^{\circ} \mathrm{N}-150^{\circ} \mathrm{E}$.

In order to display the large numeric range of values of $\lambda$, Figure 8 shows the base-10 logarithm of $|\lambda| / \lambda_{\max }$, where $\lambda_{\max }$ is the maximum value of $|\lambda|$. The most striking feature of the adjoint sensitivity is that it varies by several orders of magnitude between the regions of tidal amplification and the midbasin location. Thus, the $\eta$-field at mid-basin is primarily sensitive to the values of water depth at rather distant nearshore regions.

The sensitivity of $\eta$ to a given perturbation in $H$ is given by the inner product written in equation (22). To assess the physical significance of the sensitivity, let's assume $H^{\prime}$ is proportional to $H$, so a more relevant measure of the sensitivity is the product of $\lambda$ times $H$. This base- 10 logarithm of this field 

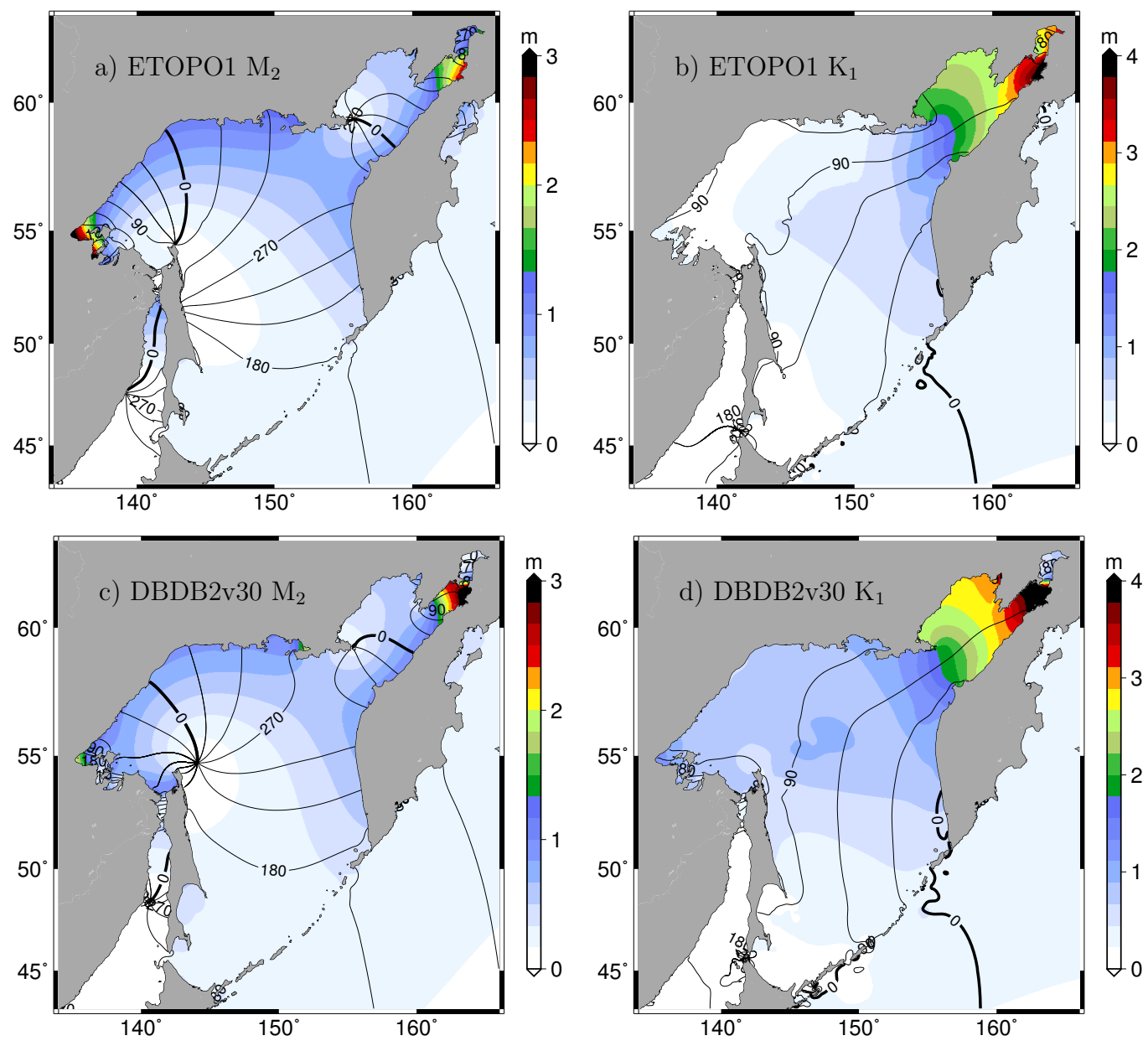

Figure 2: ETOPO1- (top) and DBDB2v30- (bottom) based tide models. Note that the color scales differ for $\mathrm{M}_{2}$ and $\mathrm{K}_{1}$ but they are the same as in Figure 1. 


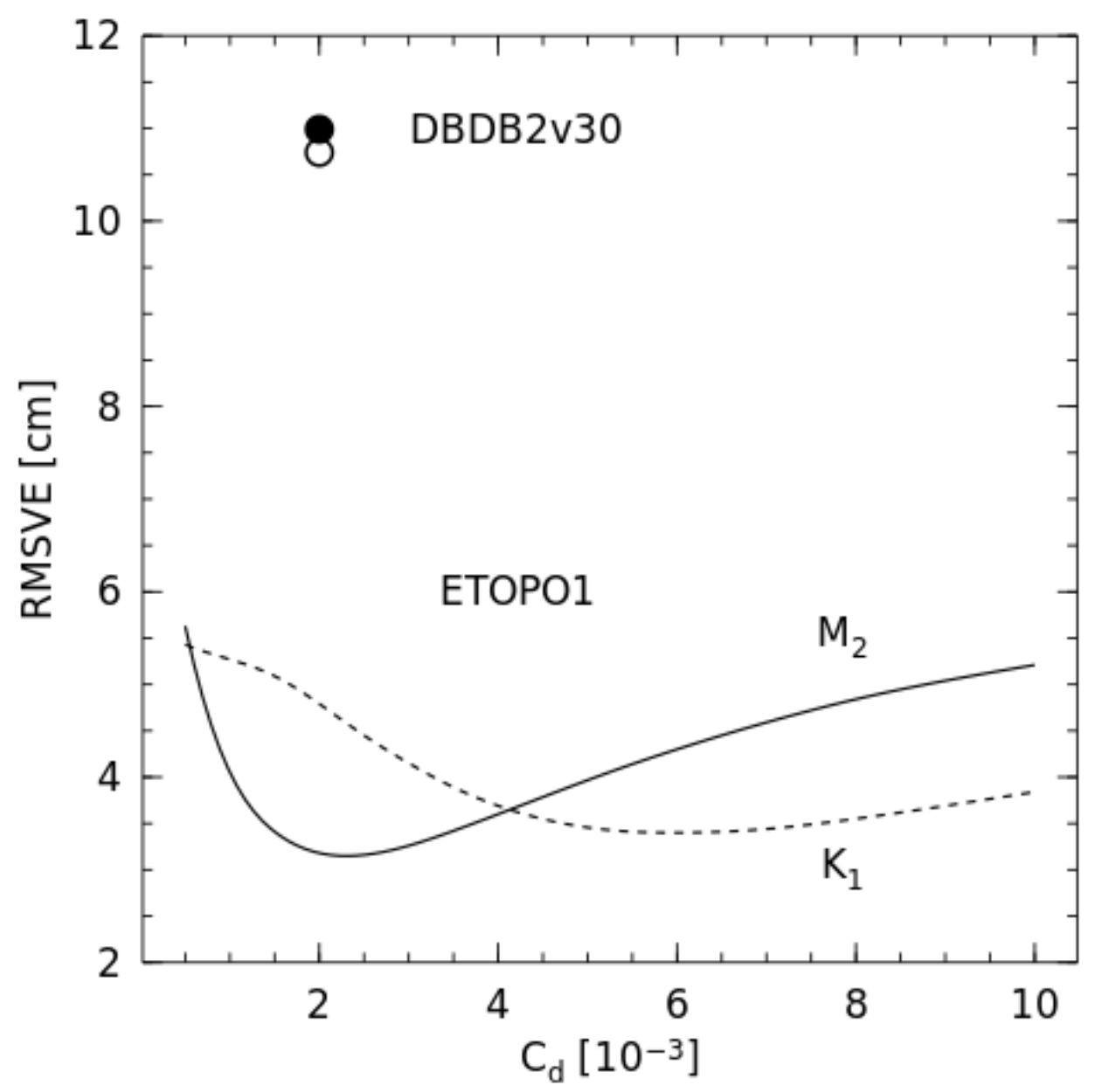

Figure 3: RMSVE as a function of $C_{d}$ using ETOPO1 topography for $\mathrm{M}_{2}$ (solid) and $\mathrm{K}_{1}$ (dashed). Points at upper left indicate the RMSVE for $\mathrm{M}_{2}$ (filled) and $\mathrm{K}_{1}$ (empty) when DBDB2v30 topography is used. Plausible changes in topography result in tides which differ by much more than can be explained by uncertainty in $C_{d}$ or in model resolution (cf., Table 1). 

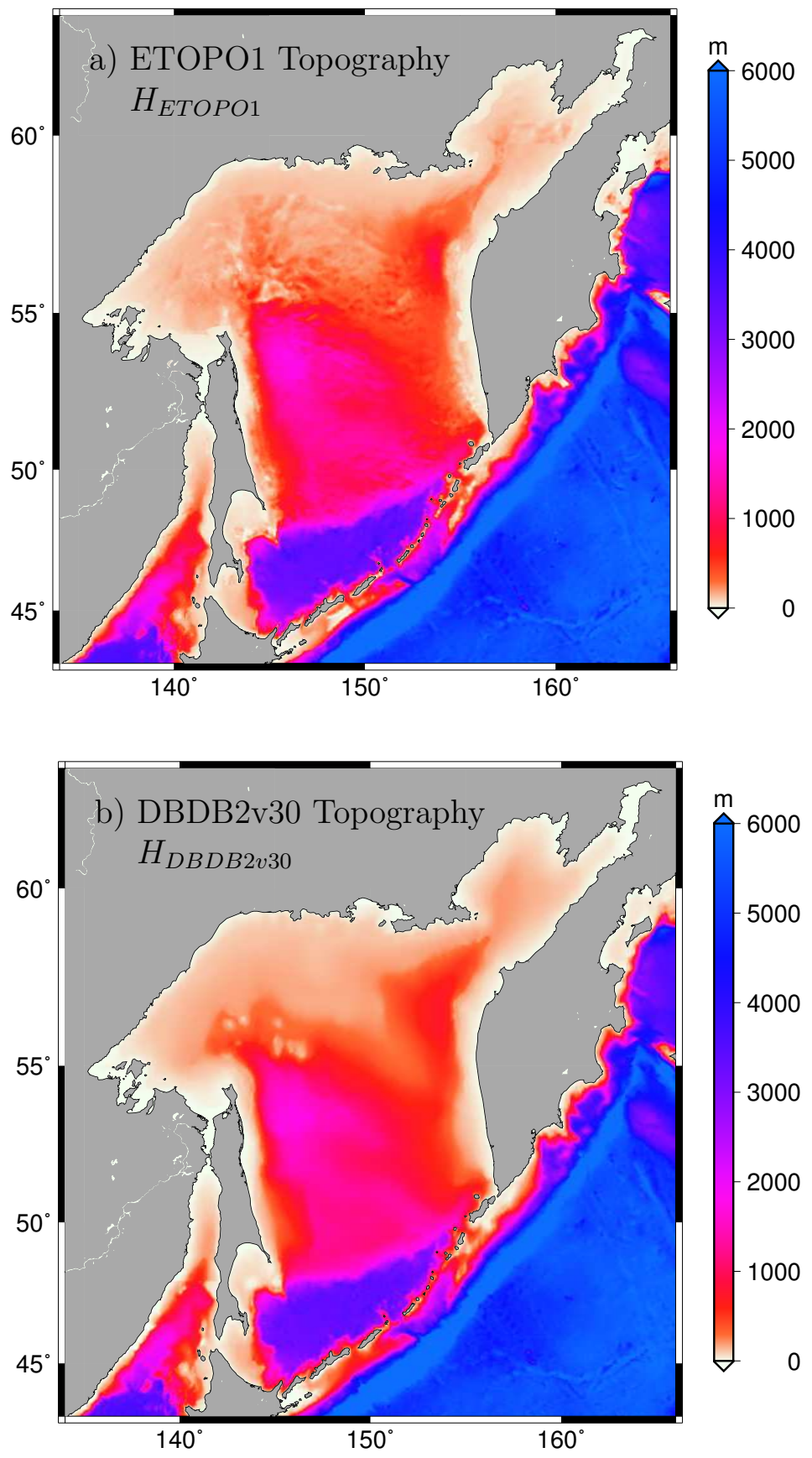

Figure 4: ETOPO1 and DBDB2v30 bottom topography. 

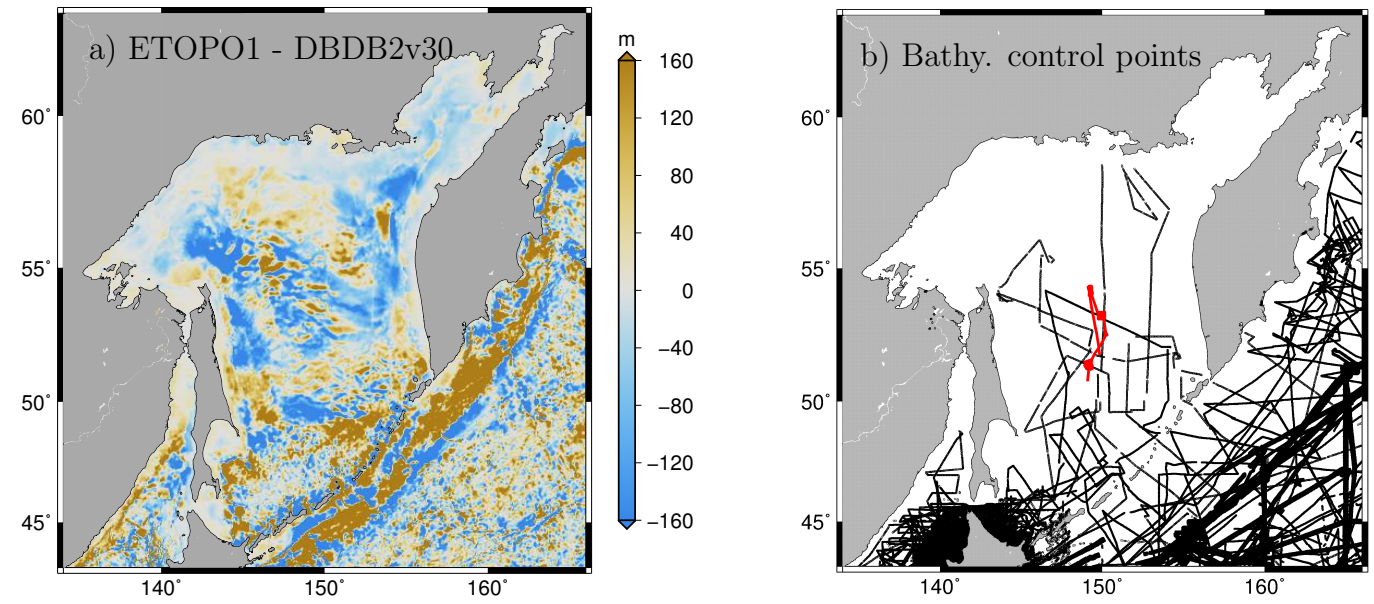

Figure 5: a) ETOPO1 minus DBDB2v30 bottom topography. b) Bathymetric control points used in Smith and Sandwell topography v. 9.1, which slightly pre-dates ETOPO1. The red points are the locations of independent bathymetry (JAMSTEC cruise MR06-04) used to validate the topographic grids.

normalized by its maximum value (Figure 9) illustrates again the degree to which shallow, near-resonant, regions control the tidal elevation throughout the basin, even when the range of potential topographic perturbations is scaled with the local water depth. In this case, a $1 \%$ change in water depth at sites within Udskaya Guba (the dark-shaded regions in the western bay) has the same impact as a $30 \%$ change in water depth at the measurement site (light-green shading near the red star at mid-basin).

The non-log-scaled version of this field (Figure 10) illustrates how the sign of the topographic perturbation is related to changes in the in-phase component of $\eta$ at the measurement site. These spatial patterns reflect the signs of the terms comprising $\lambda$ in equation (18). Most of the sensitivity 


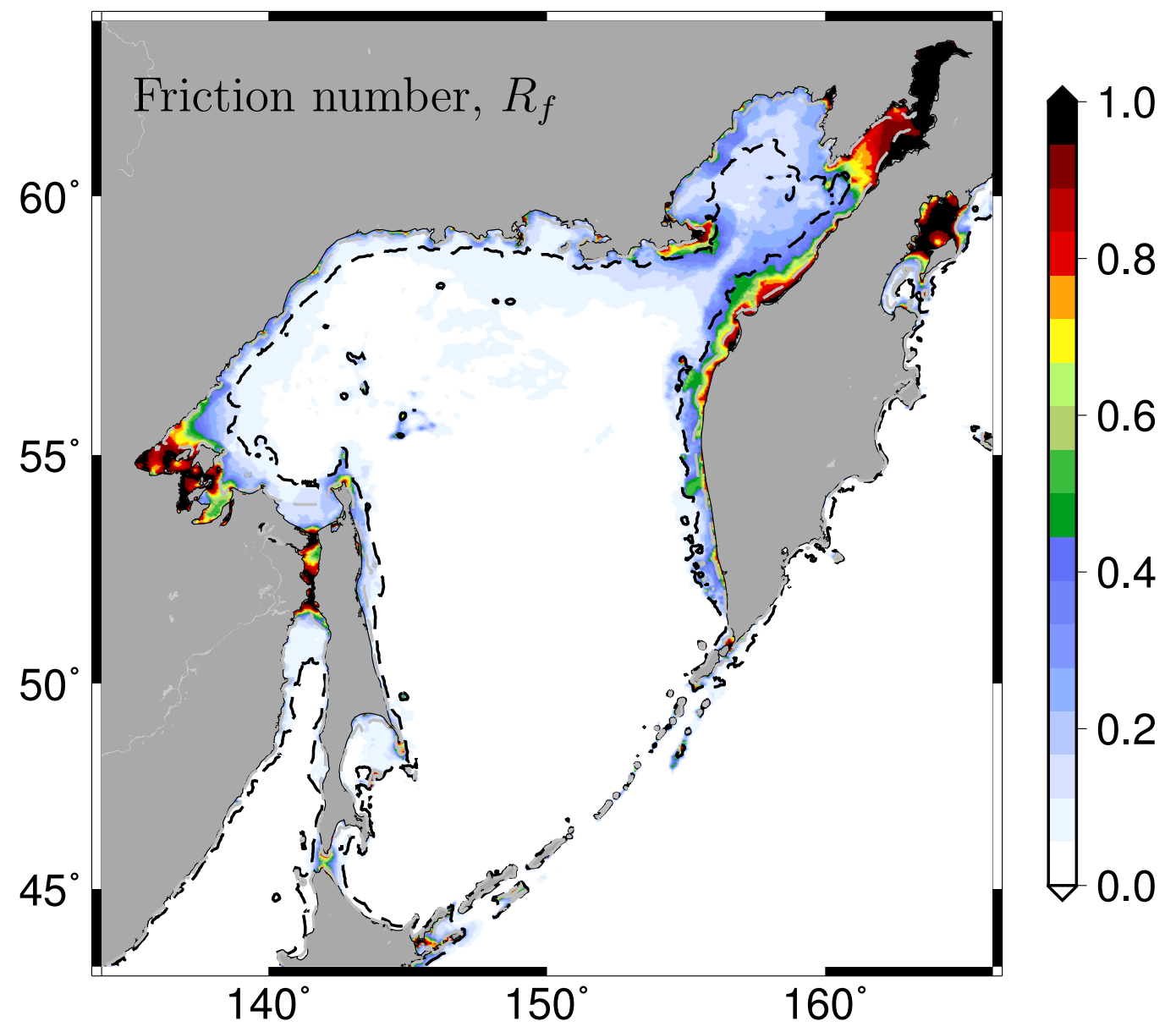

Figure 6: Friction number, $R_{f}$. The dashed line, most visible near the northern coast, indicates the $100 \mathrm{~m}$ depth contour. 

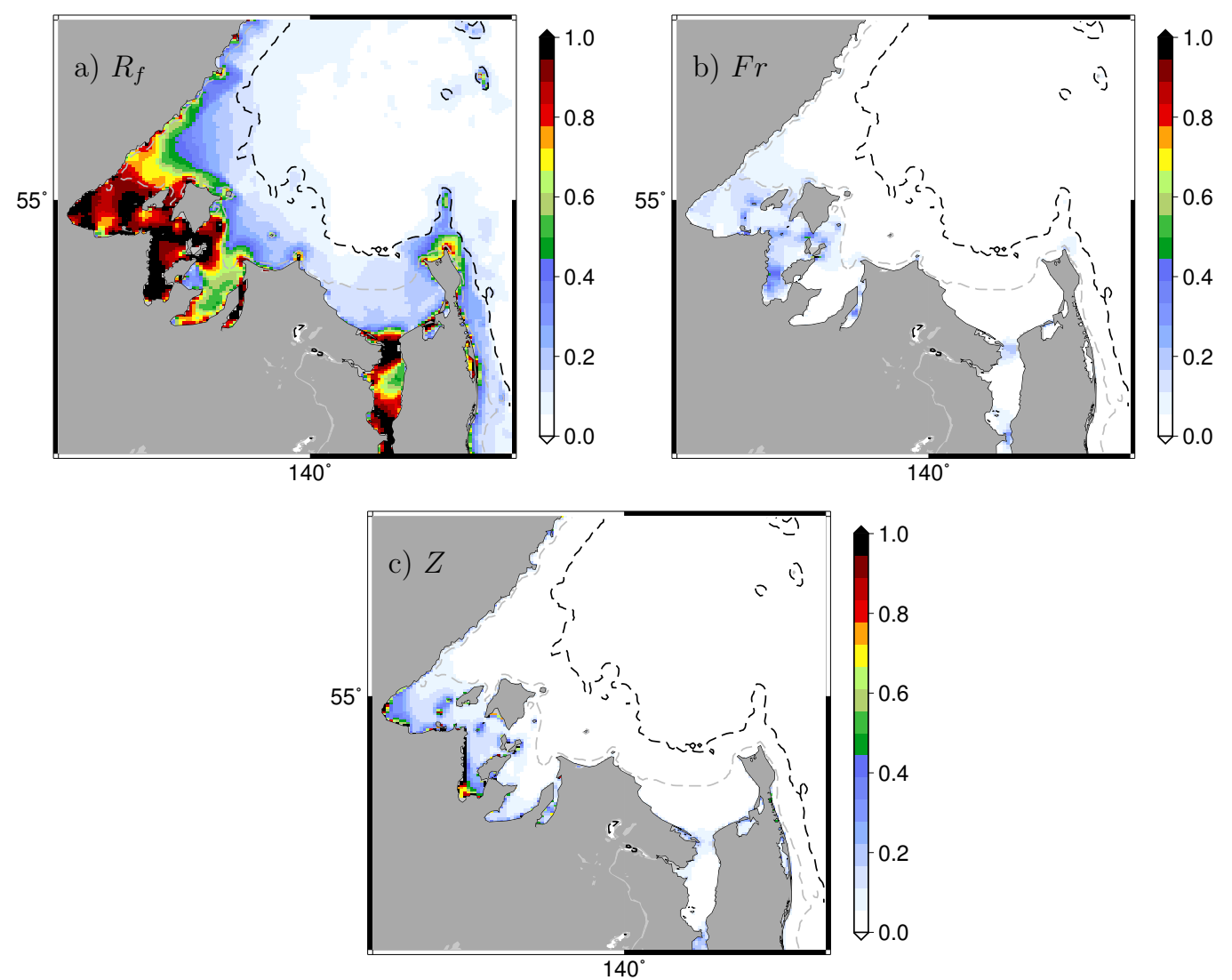

Figure 7: Terms balances, zoomed. a) $R_{f}$, friction number. b) $F r$, Froude number. c) $Z$, vertical excursion number. Solid dashed line indicates the $100 \mathrm{~m}$ depth contour; gray dashed line indicates the $30 \mathrm{~m}$ depth contour. 
results from the frictional term,

$$
C_{d} u_{f} \frac{\boldsymbol{\mu}^{*(k)} \cdot \mathbf{U}^{(k)}}{H^{2}},
$$

with the magnitude of the term largely caused by the smallness of $H$. The geometry of the bays also leads to near-resonance and amplifies the adjoint $\boldsymbol{\mu}$ fields, too, just as in the LTE.

In comparison with the sensitivity to topography, the sensitivity to the drag coefficient is much smaller (Figure 11). The scaling of $\lambda$ by $H$ and $c$ by $C_{d}$ makes the numeric values directly comparable in the sense that same percentage perturbation in either $H$ or $C_{d}$ would yield a proportional change in the in-phase component of $\eta$ at the measurement site. Because of the $1 / H$ scaling of $c$, compared to the $1 / H^{2}$ scaling of $\lambda$, the sensitivity to $C_{d}$ is limited to the near-coastal areas, and it is much smaller than the sensitivity to $H$. The sensitivity to changes in $C_{d}$ may be regarded as measure of sensitivity to changes in the other frictional parameters, $u_{0}$ and $\gamma_{f}$, since these both multiply $C_{d}$ in the expressions for the drag. Note that the dimensional values of $H \lambda$ and $C_{d} c$ shown are comparable to each other.

Other sensitivity fields have been computed corresponding to each of the 270 measurement sites in Figure 1a and for measurements of both the inphase and quadrature components of $\mathrm{M}_{2}$ and $\mathrm{K}_{1}$, for 1080 distinct measurement operators, $\kappa_{i}$, in total. Perhaps the most striking feature of these sensitivity fields is their great visual similarity. Essentially all the sensitivity fields for $\eta$ measurements in mid-basin are dominated by the near-resonant bays (not shown).

The similarity may be quantified by looking at the degree of linear independence of the sensitivity fields, $\lambda_{i}$, resulting from different measure- 
ments, $i=1, \ldots, 1080$. This has been done by computing the singular value decomposition of the matrix of inner products, $W=\int_{\mathcal{D}} \lambda_{i} \lambda_{j}$, and the depth-weighted version of this matrix, $W_{H}=\int_{\mathcal{D}} \lambda_{i} H^{2} \lambda_{j}$, corresponding to the depth-weighted sensitivities shown above. The singular spectrum of $W$ (Golub and Van Loan, 1989) indicates the linear dependence of the sensitivity fields, as exhibited by the rapid decay of the singular values with increasing index (Figure 12a). The singular spectrum of $W_{H}$ decays more slowly, but even in this case, the decay over the first 10 singular modes is almost as fast as in the unweighted case. Another measure of the degree of linear dependence is the cumulative sum of the singular values compared to their total (the trace of the matrix). In the unweighted case, more than 99\% of the total sensitivity variance is contained in the first 10 modes (Figure $12 \mathrm{~b}$ ); for the weighted sensitivities the first 10 modes contain about $90 \%$ of the sensitivity variance.

\section{Discussion}

The present work has quantified the sensitivity of tidal water elevations to bottom topography, friction, and other factors in the Sea of Okhotsk.

The motivation for this study was primarily to understand the difficulties with identification of bottom topography from measurements of tidal water elevation using variational data assimilation at continental-shelf scale. Experiments in the Sea of Okhotsk and in the South China Sea indicated that in realistic identical-twin type experiments, it is difficult to accurately reconstruct the bottom topography field from water level measurements (not shown). Detailed analysis of an idealized one-dimensional tide/wave model 


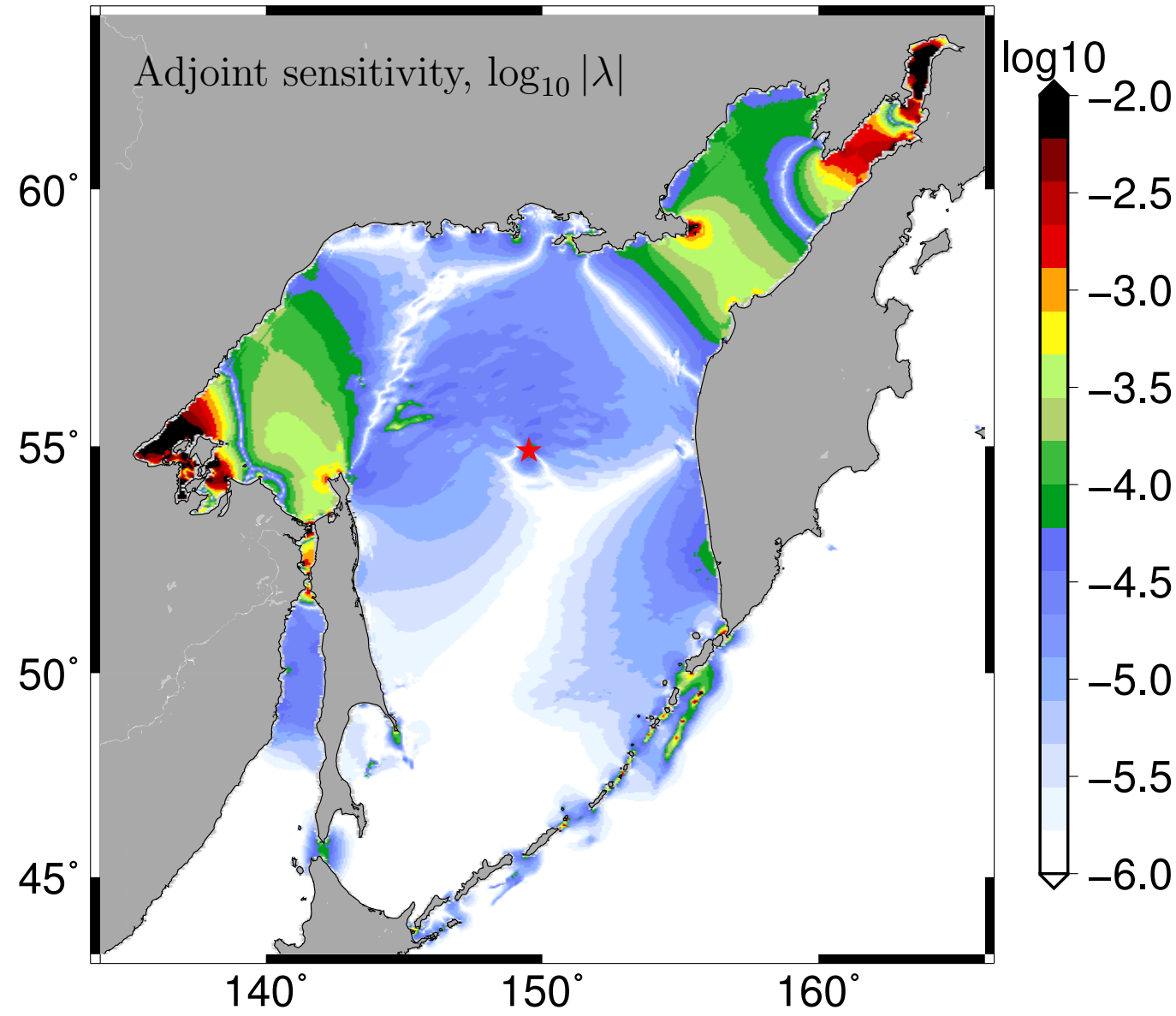

Figure 8: Adjoint sensitivity. The logarithm of the absolute value of the adjoint sensitivity, $\lambda$, is shown for an $\eta$ measurement near mid-basin indicated with the red star. The tidal elevation is most sensitive to the topography in the bays where tidal resonant amplification is large. 


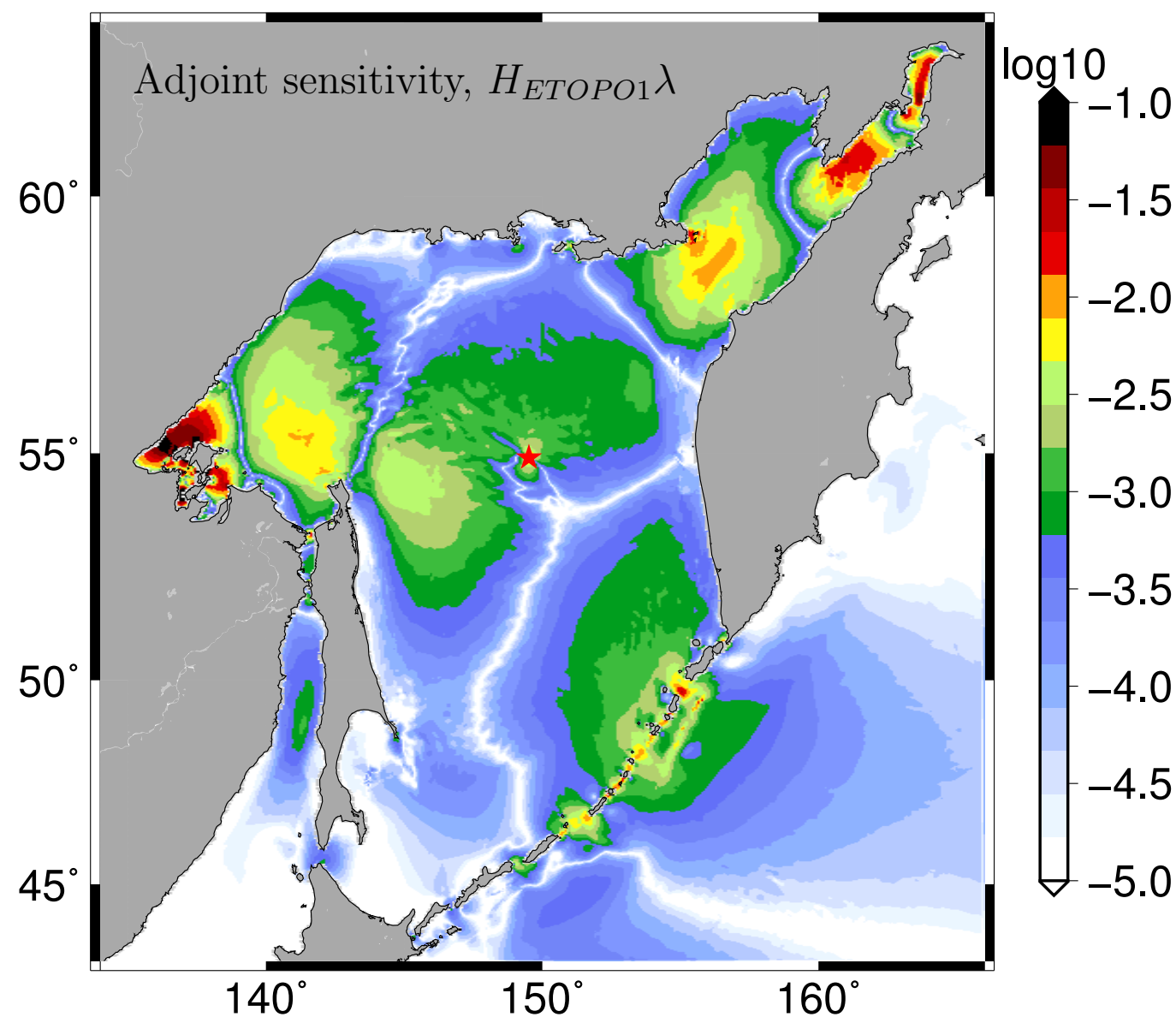

Figure 9: Adjoint sensitivity multiplied by $H, \log$-scaled. The logarithm of the absolute value of $H \lambda$ is shown for the same measurement site as in Figure 8. The adjoint sensitivity is multiplied by depth to account for the size of depth changes in the sensitivity. 


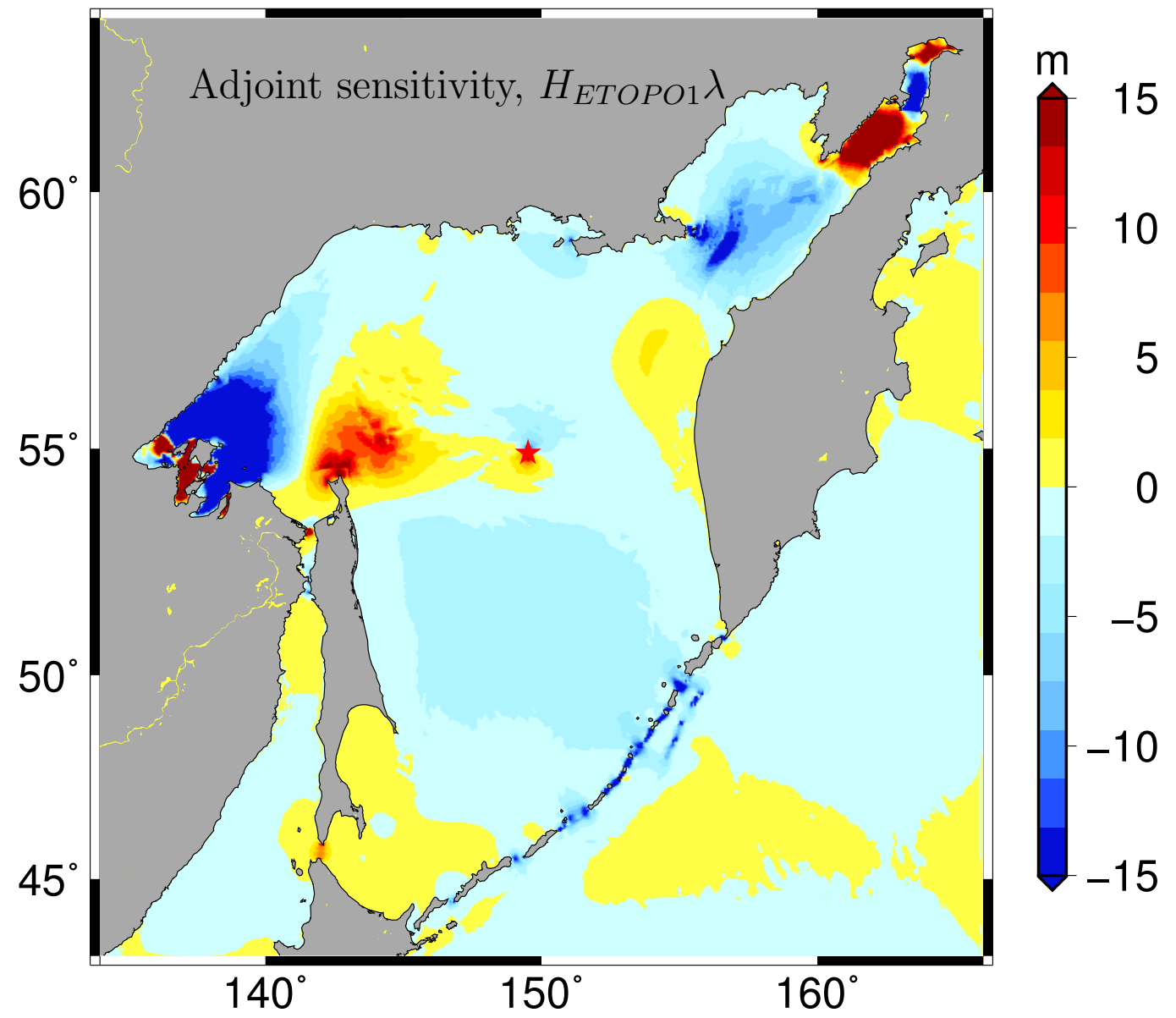

Figure 10: Adjoint sensitivity multiplied by $H$, non-log-scale. 

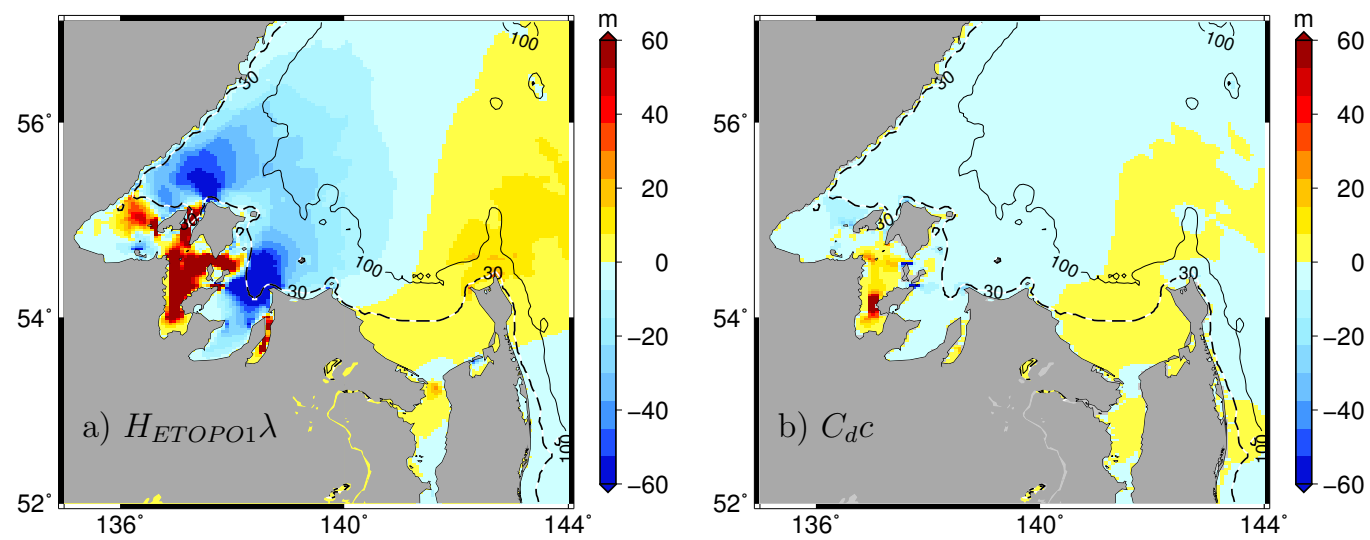

Figure 11: Adjoint sensitivities, zoomed non-log-scale. The $100 \mathrm{~m}$ and $30 \mathrm{~m}$ depth contours are also shown.
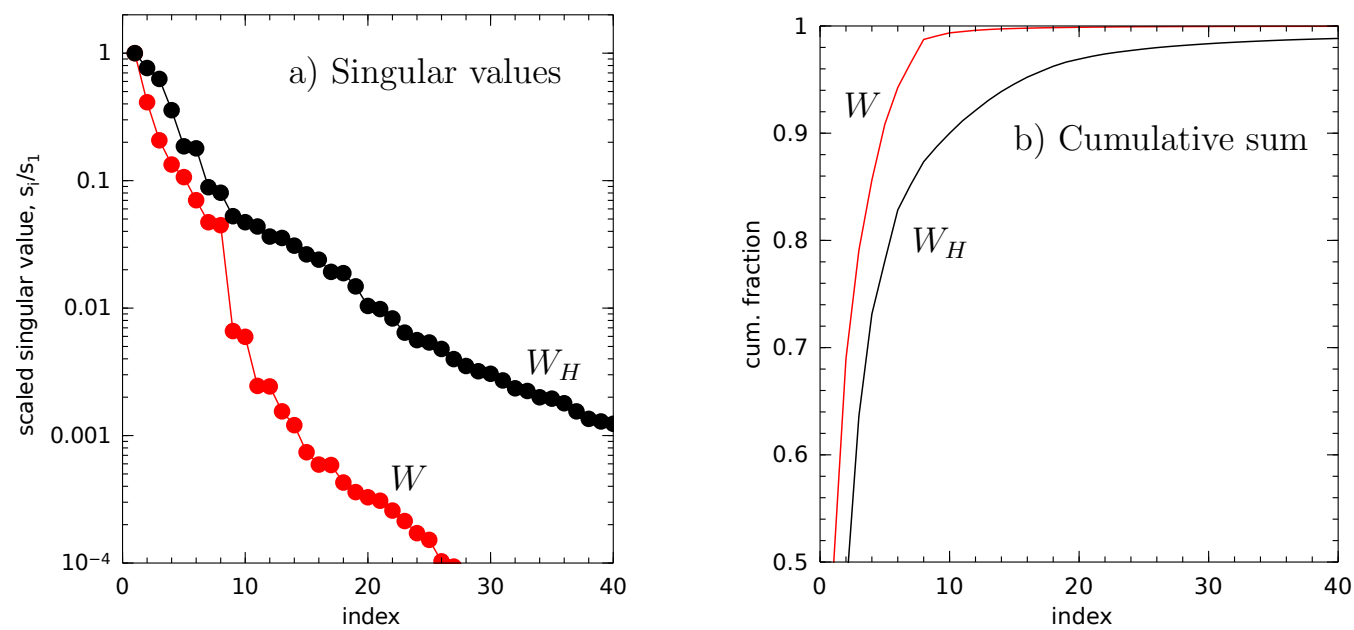

Figure 12: Analysis of linear dependence of topographic sensitivity. (a) The spectra of singular values of the matrices $W=\int_{\mathcal{D}} \lambda_{i} \lambda_{j}$ (red) and $W_{H}=\int_{\mathcal{D}} \lambda_{i} H^{2} \lambda_{j}$ (black) indicate the degree to which the adjoint sensitivity functions are linearly dependent. The controllability of the tidal surface elevation is determined by very few degrees of freedom of the bottom topography. (b) The cumulative sum of the singular spectra indicates that the first 10 degrees of freedom account for $99 \%$ (red, $W$ ) or $90 \%$ (black, $W_{H}$ ) of the $\eta$ variance controlled by $H$, for the unweighted and weighted cases, respectively. 
found that near-resonant continental shelves presented special difficulties because of the sensitivity to processes in the region of resonant amplification (Zaron, 2016). Because of the small spatial scale of these regions, they are necessarily under-observed compared to the remainder of the domain; and the resonant amplification is associating with poor conditioning and a reduction in the degrees of freedom which can be identified.

In the interests of space, the present study has investigated adjoint sensitivities in a realistic two-dimensional tide model without showing the complete inversion for topography. A thorough development of the topographic estimation problem would involve one additional element, namely, the specification of a spatial error model for the topography. Such a development is lengthy and involves the consideration of multiple sources of bathymetry, and it is logically separate from the sensitivities discussed herein. Nonetheless, the scaling of the topographic sensitivity by $H$ provides a more interpretable measure of sensitivity and is directly relevant to statistical models which parameterize the fractional uncertainty of $H$. If the difference in topography, $\Delta H=H_{E T O P O 1}-H_{D B D B 2 v 30}$, is regarded as a plausible estimate for the topographic error, one useful conclusion from the study of the degrees of freedom of the $W_{H}$ matrix is that the space spanned by the weighted sensitivity functions $\left\{H \lambda_{i}\right\}$ is very limited. For example, in the present case, projecting $\Delta H$ onto the first forty eigenmodes of the $W_{H}$ matrix only explains one percent of the variance of the $\Delta H$ field.

The results with this shelf-scale model stand in contrast to findings in riverine and nearshore ocean models, which have been used successfully to identify bottom topography from water level and other measurements. The 
reason for this can be explained by the spatial locality of the adjoint sensitivities in the different cases. For example, in the riverine study of Zaron et al. (2011), the dominant dynamical balance was between the along-channel pressure gradient and the bottom stress. The along-channel pressure gradient was determined independently, and, therefore, there was essentially a oneto-one relationship between the observed data (near-surface current) and the bottom depth at the observation location. Thus, each current measurement provided an independent constraint on bottom depth local to the measurement site. Likewise, much of the work on nearshore models, e.g., Wilson et al. (2014), involves the assimilation of wave celerity or other quantities which provide spatially localized constraints on the water depth. Unlike these cases, for tidal dynamics in the Sea of Okhotsk, each water elevation measurement is sensitive to topography at a relatively small number of locations; the data provide non-independent observations of a small set of topographic degrees of freedom.

To what extent are these findings generalizable to settings outside the Sea of Okhotsk? The variational approach to the identification of topography requires both tidal elevation data and a dynamical model which are relatively more accurate than the bottom topography. In the deep ocean there is obviously no shelf-scale resonant amplification of tides, so the results are not relevant there; however, the fractional uncertainty of topography is much smaller than the dynamical or data uncertainties, so the prospect of improving the topography there is a moot point. It is on the continental shelves where bathymetry is sparse and where the gravimetric topography is inaccurate that one might wish to apply the variational approach; but small- 
scale resonant amplification is not uncommon near the coast, and it appears that the variational methodology is fundamentally flawed for identifying topography in most cases of practical interest.

In contrast to the negative outlook for identification of topography, the present results suggest the potential for monitoring coastal processes using offshore altimeter measurements. For example, the dissipation of tidal currents near the edges of some Antarctic floating ice shelves is apparently a sensitive function of the ice shelf thickness (Mueller, 2014). The latitude of the ice shelves is poleward of the region sampled by the highly-accurate TOPEX/POSEIDON-Jason series of satellite altimeters; however, it may be possible to use these more distant altimeter data to either hindcast or monitor ice shelf thickness or extent.

The present results are consistent with the findings of other studies that indicate the tidal fields can be optimized treating the bottom topography as a control parameter (e.g., Ngodock et al. 2016). In that case, the goal is to improve $\eta$ or other derived quantities in the tide model, rather than making verifiably improved estimates of the bottom topography per se. The lack of linear dependence of the adjoint sensitivity functions suggests that a small number of degrees of freedom are necessary to effect significant changes in the tides by adjusting the topography.

\section{Summary}

The sensitivity of barotropic tides to bottom topography and frictional parameters has been studied in a model for the Sea of Okhotsk. This region was chosen because of the paucity of bathymetry data in the region and 
the possibility of using satellite altimeter data to better identify the bottom topography using variational inverse methods. Sensitivity to topography and other factors was studied using both the direct and adjoint sensitivity. In the former approach, various perturbations to the nominal model were applied to examine their impact; in the latter approach, the sensitivities were computed using the adjoint of the tangent linearization of the dynamical model.

Direct comparisons of the tide models was conducted at different spatial resolutions, using different drag coefficients, and using different topographies. Amongst these factors it was found that plausible changes in topography provided the largest impact on the tidal elevations, as measured by comparison with tides observed by satellite altimetry. Although the model's realism is limited by the omission of nonlinear terms, flooding and drying processes, and the finite number of tidal frequencies used, the influence of these factors appears to be smaller than either the topography or frictional parameterizations.

The adjoint sensitivities computed with the model clarify the roles of both topography and friction in determining the tidal elevation. The principal finding is the extent to which small-scale near-resonant amplification controls tides at the basin scale. This is not a new finding (Lyard and Genco, 1994; Lefevre et al., 2000); instead, the results clarify the relatively few degrees of freedom in the topography which control the tides. The nature of the control depends on both the geometry of the basin, which permits the small-scale amplification, and also the presence of a bottom dissipation, which amplifies the sensitivity in shallow water by the factor $1 / H^{2}$.

The findings reiterate the conclusions of Zaron (2016) regarding the signif- 
icance of small-scale near-resonant amplification for the topographic identification problem using tidal dynamics. In contrast to results with riverine and nearshore ocean models, where the observations are more closely related to topographic features localized to the measurement location, the tidal dynamics and resonance creates a non-local relationship and lack of independence of the data. As in the idealized one-dimensional study of Zaron (2016), it is hypothesized that the topographic identification problem is sensitive to the details of the spatial covariance model for the topography in regions of tidal amplification. This fundamentally limits the applicability of inverse approaches for identification of topography, and provides an additional rationale for the collection and sharing of high quality bathymetry data to enable improved ocean modeling.

\section{Acknowledgments}

Support from the NASA Ocean Surface Topography Science Team award \#NNX13AH06G is gratefully acknowledged. Satellite altimeter data used here were extracted from the Radar Altimeter Database System (RADS; http://rads.tudelft.nl/rads/rads.shtml), an invaluable resource. The software for this project was derived from the Oregon State Tidal Inversion Software (OTIS; http://volkov.oce.orst.edu/tides/otis.html), developed and kindly provided by Gary Egbert and Lana Erofeeva. 


\section{References}

Amante, C., Eakins, B. W., 2009. ETOPO1 1 arc-minute global relief model: procedures, data sources and analysis. Technical Memorandum NESDIS NGDC-24, NOAA, Washington, DC.

Andrews, B., Hopper, C., 2011. The Ricci Flow in Riemannian Geometry. No. 2011 in Lecture Notes in Mathematics. Springer, New York.

Bennett, A. F., 1992. Inverse Methods in Physical Oceanography, 1st Edition. Cambridge University Press, New York.

Bennett, A. F., 2002. Inverse Modeling of the Ocean and Atmosphere. Cambridge University Press, New York.

Carrère, L., Le Provost, C., Lyard, F., 2004. On the statistical stability of the $\mathrm{M}_{2}$ barotropic and baroclinic tidal characteristics from along-track TOPEX/Poseidon satellite altimetry analysis. J. Geophys. Res. 109 (C3), c03033.

Cea, L., French, J. R., 2012. Bathymetric error estimation for the calibration and validation of estuarine hydrodynamic models. Est. Coast. and Shelf Sci. 100, 124-132.

Dronkers, J. J., 1964. Tidal Computations in Rivers and Coastal Waters. North Holland Publishing Co.

Egbert, G. D., Bennett, A. F., Foreman, M., 1994. TOPEX/POSEIDON tides estimated using a global inverse model. J. Geophys. Res. 99, 24,82124,852 . 
Egbert, G. D., Erofeeva, S. Y., 2002. Efficient inverse modeling of barotropic ocean tides. J. Atm. and Ocean. Tech. 19, 183-204.

Errico, R. M., 1997. What is an adjoint model? Bull. Am. Met. Soc. 78 (11), 2577-2591.

Godin, G., 1986. Modification by an ice cover of the tide in James Bay and Hudson Bay. Arctic 39, 6567.

Golub, G., Van Loan, C., 1989. Matrix Computations, 2nd Edition. Johns Hopkins University Press, Baltimore.

Grant, W. D., Madsen, O. S., 1979. Combined wave and current interactions with a rough bottom. J. Geophys. Res. 84, 1797-1808.

Hirose, N., 2005. Least-squares estimation of bottom topography using horizontal velocity measurements in the Tsushima/Korea Straits. J. of Oceanogr. 61, 789-794.

Hirose, N., Fukumori, I., Zlotnicki, V., Ponte, R. M., 2001. Modeling the high-frequency barotropic response of the ocean to atmospheric disturbances: Sensitivity to forcing, topography, and friction. J. Geophys. Res. 106 (C12), 30987-30995.

Inazu, D., Sato, T., Miura, S., Ohta, Y., Nakamura, K., Fujimoto, H., Larsen, C. F., Higuchi, T., 2009. Accurate ocean tide modeling in southeast Alaska and large tidal dissipation around Glacier Bay. J. of Oceanogr. 65, 335-347.

Jakobsson, M., Armstrong, A., Calder, B., Huff, L., Mayer, L., Ward, L., 2005. On the use of historical bathymetric data to determine changes in 
bathymetry: an analysis of errors and application to Great Bay Estuary, NH. Int. Hydro. Rev. 6 (3), 25-41.

Jakobsson, M., Calder, B., Mayer, L., 2002. On the effect of random errors in gridded bathymetric compilations. J. Geophys. Res. 107 (B12), 2350.

Ko, D.-S., 2010. DBDB2 v. 3.0 digital bathymetry. personal communication. URL https://www7320.nrlssc.navy.mil/DBDB2_WWW

Kowalik, Z., Polyakov, I., 1998. Tides in the Sea of Okhotsk. J. Phys. Oceanogr. 28, 1389-1409.

Lavelle, J. W., Mofjeld, H. O., 1983. Effects of time-varying viscosity on oscillatory turbulent channel flow. J. Geophys. Res. 88 (C12), 7607-7616.

Lefevre, F., LeProvost, C., Lyard, F. H., 2000. How can we improve a global ocean tide model at a regional scale? A test on the Yellow Sea and the East China Sea. J. Geophys. Res. 105 (C4), 8707-8725.

Lyard, F., Genco, M. L., 1994. Optimisation methods for bathymetry and open boundary conditions in a finite element model of ocean tides. J. Comp. Phys. 114 (2), 234-256.

Marks, K., Smith, W., Sandwell, D., 2010. Evolution of errors in the altimetric bathymetry model used by Google Earth and GEBCO. Marine Geophysical Research 31, 223-238.

Marks, K., Smith, W. H., 2008. An uncertainty model for deep ocean single beam and multibeam echo sounder data. Mar. Geophys. Res. 29 (4), 239250. 
Marks, K. M., Smith, W. H., 2005. 2,500m isobath from satellite altimetry - accuracy assessment in light of IHO S-44 standards. International Hydrographic Review 6 (2), 1-11.

Marks, K. M., Smith, W. H., 2012. Radially symmetric coherence between satellite gravity and multibeam bathymetry grids. Mar. Geophys. Res. $33(3), 223-227$.

Mueller, R. D., 2014. The effects of thermodynamic parameterizations, iceshelf geometry, and tides on modeled basal melting of Weddell Sea ice shelves. Ph.D. thesis, College of Oceanic and Atmospheric Sciences, Oregon State University, Corvallis, Oregon, USA.

Ngodock, H. E., Souopgui, I., Wallcraft, A. J., Richman, J. G., Shriver, J. F., Arbic, B. K., 2016. On improving the accuracy of the $\mathrm{M}_{2}$ barotropic tides embedded in a high-resolution global ocean circulation model. Ocean Mod. $97,19-26$.

Organization, I. H., 1998. Standards for hydrographic surveys. Special Publication 44, International Hydrographic Bureau, Monaco.

Perlin, A., Moum, J. N., Klymak, J. M., Levine, M. D., Boyd, T., Kosro, P. M., 2005. A modified law-of-the-wall applied to oceanic bottom boundary layers. J. Geophys. Res. 110, C10S10.

Ray, R. D., 1998. Spectral analysis of highly aliased sea-level signals. J. Geophys. Res. 103 (C11), 24991-25003.

Shcherbina, A. Y., Talley, L. D., Rudnick, D. L., 2004. Dense water formation 
on the northwestern shelf of the Okhotsk Sea: 1. Direct overservations of brine rejection. J. Geophys. Res. 109, C09S08.

Smith, W. H., 1993. On the accuracy of digital bathymetric data. J. Geophys. Res. 98 (B6), 9591-9603.

Smith, W. H., Sandwell, D. T., 1994. Bathymetric prediction from dense satellite altimetry and sparse shipboard bathymetry. J. Geophys. Res. 99, 21803-21824.

Smith, W. H., Sandwell, D. T., 1997. Global sea floor topography from satellite altimetry and ship depth soundings. Science 277, 1956-1962.

Snyder, R. L., Sidjabat, M., Filloux, J. H., 1979. A study of tides, setup and bottom friction in a shallow semi-enclosed basin. Part II: tidal model and comparison with data. J. Phys. Oceanogr. 9, 170-188.

Stammer, D., Ray, R. D., Andersen, O. B., Arbic, B. K., Bosch, W., Carrre, L., Cheng, Y., Chinn, D. S., Dushaw, B. D., Egbert, G. D., Erofeeva, S. Y., Fok, H. S., Green, J. A. M., Griffiths, S., King, M. A., Lapin, V., Lemoine, F. G., Luthcke, S. B., Lyard, F., Morison, J., Mller, M., Padman, L., Richman, J. G., Shriver, J. F., Shum, C. K., Taguchi, E., Yi, Y., 2014. Accuracy assessment of global barotropic ocean tide models. Rev. of Geophys. 52 (3), 243-282.

Ten-Brummelhuis, P. G., Heemink, A. W., van den Boogard, H., 1993. Identification of shallow sea models. Int. J. for Num. Meth. Fluids 17, 637-665.

Wessel, P., Chandler, M., 2011. The spatial and temporal distribution of 
marine geophysical surveys. Acta Geophysica 59, 55-71, 10.2478/s11600010-0038-1.

URL http://dx.doi.org/10.2478/s11600-010-0038-1

Wilson, G. W., Özkan-Haller, H. T., Holman, R. A., Haller, M. C., Honegger, D. A., Chickadel, C. C., 2014. Surf zone bathymetry and circulation predictions via data assimilation of remote sensing observations. J. Geophys. Res. 119 (3), 1993-2016.

Xing, J., Davies, A. M., 1995. The influence of mixing length formulation and stratification upon tidal currents in shallow seas. Est. Coast. and Shelf Seas $42,417-456$.

Zaron, E. D., 2016. On the observability of bottom topography from measurements of sea surface height. Ocean Mod., 55-63.

Zaron, E. D., Pradal, M., Miller, P. D., Blumberg, A. F., Georgas, N., Li, W., Cornuelle, J. M., 2011. Bottom topography mapping via nonlinear data assimilation. J. Atm. and Ocean. Tech. 28, 1606-1623. 